\title{
Comparative Analysis of Solid AFO vis-à-vis Articulated AFO using Flexible Ankle Hinges in Children with Cerebral Palsy Spastic Diplegia Age Group 5-12 Years in Terms of Gait Parameters
}

\author{
Haribhau S. Dongre ${ }^{1}$, Kishan Singh ${ }^{2}$, Lukeshkumar R. Bhuyar ${ }^{3}$ \\ ${ }^{1}$ Lecturer $\mathrm{P} \& \mathrm{O},{ }^{2,3}$ Demonstrator $\mathrm{P} \& \mathrm{O}$, \\ Dept. of Prosthetics and Orthotics, All India Institute of Physical Medicine \& Rehabilitation, Mahalaxmi, \\ Mumbai-400034. \\ Corresponding Author: Lukeshkumar R. Bhuyar
}

DOI: https://doi.org/10.52403/ijhsr.20220211

\begin{abstract}
In this study, we have studied 16 subjects with Cerebral Palsy spastic diplegia age group 5-12 years (9 male, 7 female) with GMFC level 1, 2 or 3 with the consent of their parents. We had evaluated these subjects and took their measurements and prepared Static AFOs and given it to the subjects to use it for 30 days. The spatiotemporal gait parameters like step length, stride length, speed and cadence were recorded with static AFOs and then given with Articulated AFOs for next 30 days. The reading was recorded for Articulated AFOs. The data collected were analyzed using paired t test using software InStat GraphPad. The results of the study shown that the performance of subjects was better with Articulated AFOs in comparison with Static AFOs. These results will help the professionals to choose the appropriate design for Children with Cerebral Palsy.
\end{abstract}

Key Words: Cerebral Palsy, Articulated AFO, Equinovarus, Static AFO, Gait, Spasticity.

\section{INTRODUCTION}

After reviewing recent literatures, in India there are hardly any studies done in the use of Static and Dynamic AFO using Flexible Ankle hinges (Tamarack type) to check their effectiveness in CP children with spastic diplegia.

The majority of Spastic Cerebral Palsy children exhibit high tone in the extensor muscles of the lower extremity. Spastic planter flexors and invertors pull the foot in to an equinovarus position.

In this research we aim to study the efficacy of Solid AFO vis-à-vis Articulated AFO using Flexible Ankle hinges in children with Cerebral Palsy spastic diplegia with age group 5-12 years in terms of Gait Parameters.
Objective of this study is to compare the biomechanical effectiveness of the solid AFO with articulated AFO using Flexible Ankle hinges in children with Cerebral Palsy spastic diplegia with age group 5-12 years by using the spatiotemporal parameters of the gait.

\section{MATERIALS AND METHODS}

This research was conducted at Prosthetic and Orthotic Department of Tertiary Rehabilitation Centre where Cerebral Palsy children with Spastic Diplegia in the age group 5-12 years were recruited with prior consent. The study took nine months' time duration to derive the results. Sixteen children were taken as sample size with convenience sampling and study design as Prospective interventional 
study. Both male and female were included in the study with age ranging from5-12 years. Children with Cerebral palsy spastic diplegic child with GMFC level 1,2,3 were included who do not have contracture of lower limb especially at knee and ankle and were not having visual and hearing impairment and were not having other associated neurological or orthopedics condition.

In the plan of study after obtaining consent from child's parent at the First Stage i.e. at Day 1, evaluation and assessment were done followed by measurement and cast of Plaster of Paris. The Gait of the child was analyzed without any orthosis. At the second stage i.e. on Day 10 child was fitted with Static AFO and given to use at home after proper gait training. At the third stage i.e. at Day 40 measurement and readings of parameter values with static AFO was noted and then the child was given with Articulated AFO with Flexible Ankle hinges for next 30 days. At the fourth stage i.e. on Day 70 measurement and readings of parameter values with Articulated AFO with Flexible Ankle hinges were noted and photographs were taken.
The data were recorded and analyzed using Paired " $t$ " test is used to compare the outcomes measured between both the designs of orthoses and level of significance as $p \leq 0.05$.

\section{Statistical Analysis}

The recorded data is analyzed using Paired " $t$ " test to compare the outcomes measured between both the designs of orthoses and level of significance as $\mathrm{p} \leq$ 0.05. Spatiotemporal parameters i.e. Step length, Stride length, Speed and Cadence were used. All the data are analyzed by paired " $t$ " test using software "Graph Pad Instat".

\section{RESULTS}

The results of the study can guide the practitioners to choose appropriate Orthotic design which varies from subject to subject and is influenced by body contours, climate, activity level and personal preferences.

\section{GAIT PARAMETERS: 1.1. STEP LENGTH:}

The mean step length of patients using Solid AFO is $0.3338( \pm 0.1114)$ meters and with Articulated AFO using Flexible Ankle hinges is $0.3994( \pm 0.1414)$ meters of as shown in table.

\section{STEP LENGTH WITHIN THE GROUP:}

Table 1.1: Types of Orthotic designs mean (M), standard deviation (SD), total number of subjects (N), and "t" value of step length within Solid AFO vis -a-vis Articulated AFO using Flexible Ankle hinges.

\begin{tabular}{|l|l|l|l|l|l|}
\hline Orthotic Design & M & SD & N & t-value & Remarks \\
\hline Solid AFO & 0.3338 & 0.1114 & 16 & & \multirow{2}{*}{} \\
\cline { 1 - 4 } AAFO using Flexible Ankle hinges & 0.3994 & 0.1414 & 16 & $\mathrm{t}=3.114$ & $\mathrm{P}=0.0071(\mathrm{P}<0.05)$ \\
\hline
\end{tabular}

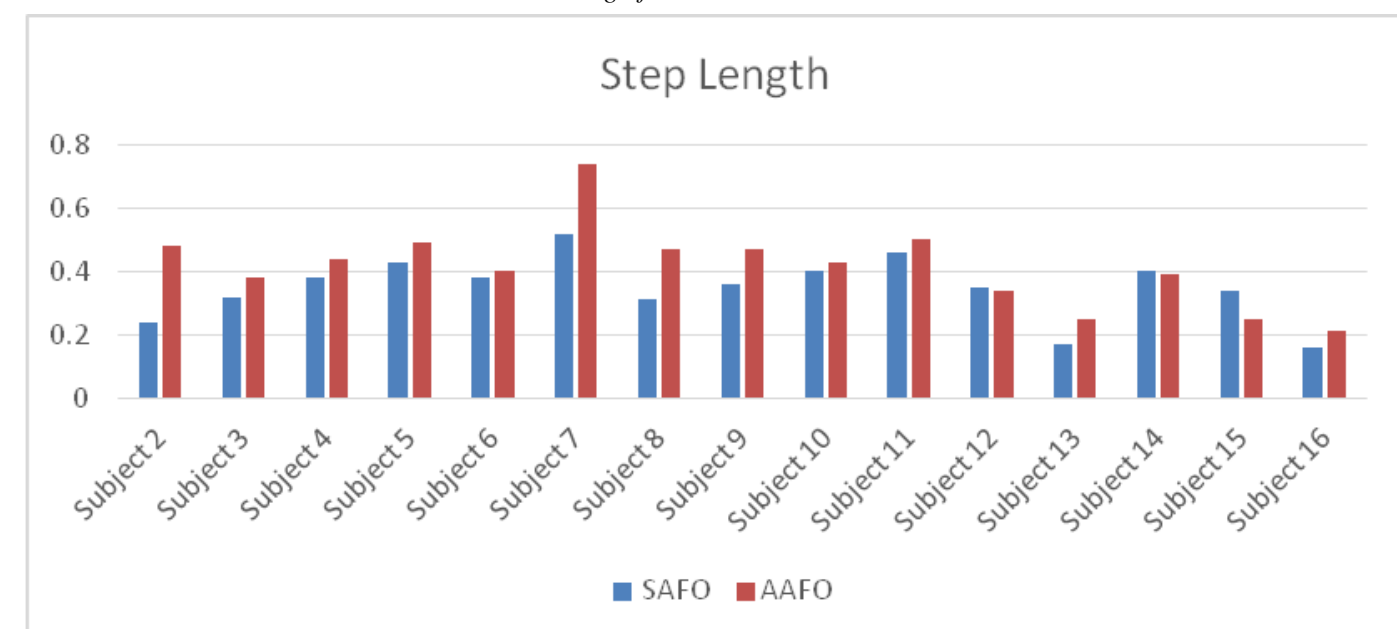

GRAPH 1.1: Step length of Solid AFO (SAFO) and Articulated AFO using Flexible Ankle hinges Tamarack type (AAFO). $X$-axis:- Step Length in meter. Y-axis: - Number of Subjects 
Haribhau S. Dongre et.al. Comparative analysis of solid AFO vis-à-vis articulated AFO using flexible ankle hinges in children with cerebral palsy spastic diplegia age group 5-12 years in terms of gait parameters.

From table, 1.1 it can be seen that the $t$ value is 3.114 which is significant at 0.05 levels with degree of freedom 4. It indicates that the mean value of Solid AFO differ significantly than Articulated AFO using Flexible Ankle hinges. Further the mean value of step length in Solid AFO whose mean value of step length is 0.3338 which is lower than that of Articulated AFO using Flexible Ankle hinges is 0.3994 (table no. 7.1.1). It may therefore be said that Articulated AFO using Flexible Ankle hinges has found to be slightly significantly superior to Solid AFO in terms of step length.

\subsection{STRIDE LENGTH:}

The mean stride length of patients using Solid AFO is $0.6531( \pm 0.1970)$ meters and with Articulated AFO using Flexible Ankle hinges is $0.7419( \pm 0.2178)$ meters of as shown in table.

\section{STRIDE LENGTH WITHIN THE GROUP:}

Table 1.2: Types of Orthotic designs mean (M), standard deviation (SD), total number of subjects (N), and " $t$ " value of stride length within Solid AFO vis -a-vis Articulated AFO using Flexible Ankle hinges (Tamarack type).

\begin{tabular}{|l|c|c|c|c|c|}
\hline Orthotic Design & M & SD & N & t-value & Remarks \\
\hline Solid AFO & 0.6531 & 0.1970 & 16 & \multirow{2}{*}{$\mathrm{t}=3.525$} & $\mathrm{P}=0.0031(\mathrm{P}<0.05)$ \\
\hline AAFO using Flexible Ankle hinges & 0.7419 & 0.2178 & 16 & & \\
\hline
\end{tabular}

From table, 1.2 it can be seen that the $t$ value is 3.525 which is significant at 0.05 levels with degree of freedom 4 . It indicates that the mean value of Solid AFO differ significantly than Articulated AFO using Flexible Ankle hinges. Further the mean value of stride length in Solid AFO whose mean value of stride length is 0.6531 which is lower than that of Articulated AFO using Flexible Ankle hinges is 0.7419 (table no. 1.2). It may therefore be said that Articulated AFO using Flexible Ankle hinges (Tamarack type) has found to be slightly significantly superior to Solid AFO in terms of stride length.

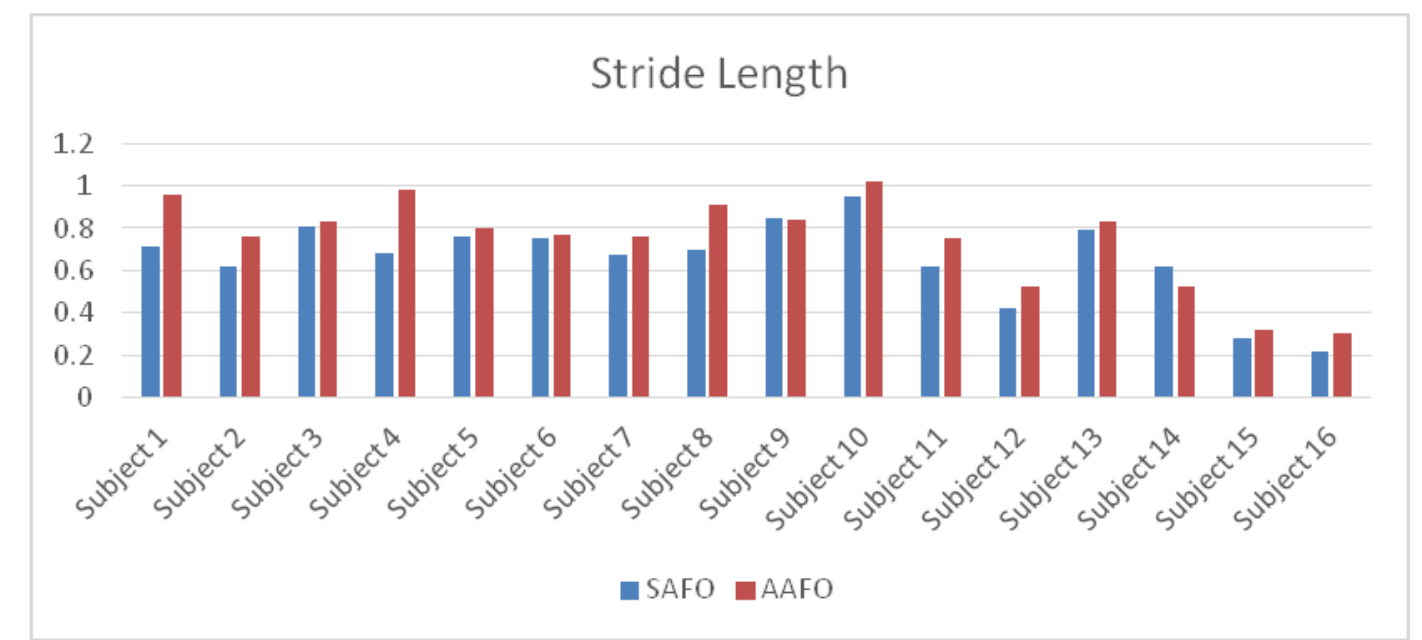

GRAPH 1.2: Stride length of Solid AFO (SAFO) and Articulated AFO using Flexible Ankle hinges Tamarack type (AAFO). $X$-axis: -Number of Subjects, $Y$-axis: - Stride length in meter

\subsection{SPEED/ VELOCITY:}

The mean Speed of patients using Solid AFO is $0.4431( \pm 0.5631)$ meters per second and with Articulated AFO using Flexible Ankle hinges is $0.2452( \pm 0.2959)$ meters per second of as shown in table.

\section{SPEED/ VELOCITY WITHIN THE GROUP:}

From table, 1.3 it can be seen that the $\mathrm{t}$ value is 4.339 which is significant at 0.05 levels with degree of freedom 4. It indicates that the mean value of Solid AFO differ significantly than Articulated AFO using Flexible Ankle hinges. Further the 
Haribhau S. Dongre et.al. Comparative analysis of solid AFO vis-à-vis articulated AFO using flexible ankle hinges in children with cerebral palsy spastic diplegia age group 5-12 years in terms of gait parameters.

mean value of Speed in Solid AFO whose mean value of Speed is 0.4431 which is lower than that of Articulated AFO using Flexible Ankle hinges is 0.2452 (table no.1.3). It may therefore be said that
Articulated AFO using Flexible Ankle hinges has found to be slightly significantly superior to Solid AFO in terms of stride length.

Table 1.3: Types of Orthotic designs mean (M), standard deviation (SD), total number of subjects (N), and " $t$ " value of Speed within Solid AFO vis -a-vis Articulated AFO using Flexible Ankle hinges.

\begin{tabular}{|l|l|l|l|l|l|}
\hline Orthotic Design & M & SD & N & t-value & Remarks \\
\hline Solid AFO & 0.4431 & 0.5631 & 16 & \multirow{2}{*}{$\mathrm{t}=4.339$} & $\mathrm{P}=0.0006(\mathrm{P}<0.05)$ \\
\cline { 1 - 3 } AAFO using Flexible Ankle hinges & 0.2452 & 0.2959 & 16 & & \\
\hline
\end{tabular}

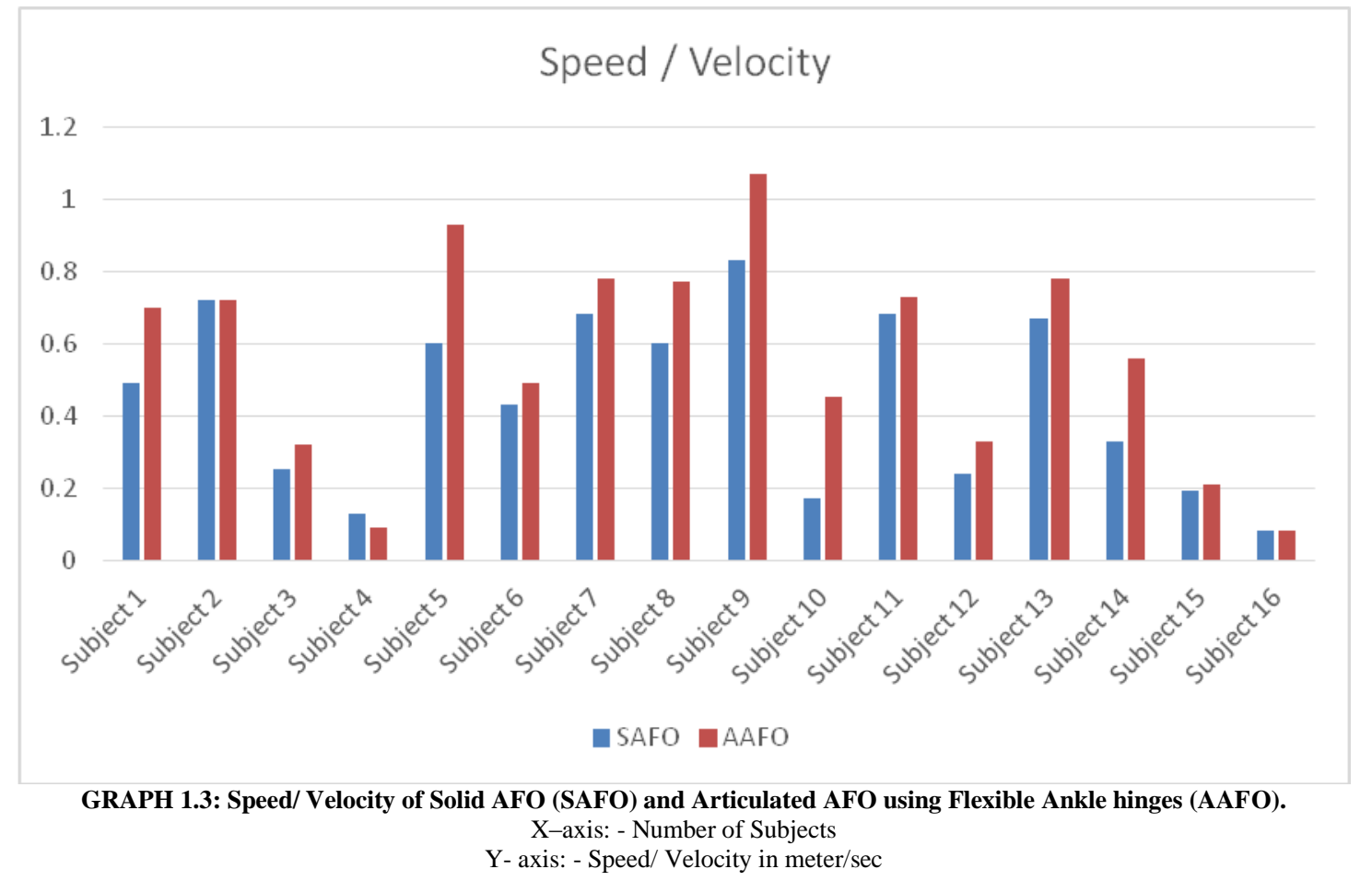

\subsection{CADENCE:}

The mean Speed of patients using Solid AFO is $91.56( \pm 35.46)$ meters per second and with Articulated AFO using Flexible Ankle hinges is $104.3( \pm 31.99)$ meters per second of as shown in table.

\section{CADENCE WITHIN THE GROUP:}

Table 1.4: Types of Orthotic designs mean (M), standard deviation (SD), total number of subjects $(N)$, and " $t$ " value of Speed within Solid AFO vis -a-vis Articulated AFO using Flexible Ankle hinges.

\begin{tabular}{|c|c|c|c|c|c|}
\hline $\begin{array}{l}\text { Orthotic } \\
\text { Design }\end{array}$ & $\mathbf{M}$ & SD & $\mathbf{N}$ & t-value & Remarks \\
\hline Solid AFO & 91.56 & 35.46 & 16 & \multirow{2}{*}{$\mathrm{t}=2.647$} & \multirow{2}{*}{$\mathrm{P}=0.0183(\mathrm{P}<0.05)$} \\
\hline AAFO using Flexible Ankle hinges & 104.3 & 31.99 & 16 & & \\
\hline
\end{tabular}

From table, 1.4 it can be seen that the $\mathrm{t}$ value is 2.647 which is significant at 0.05 levels with degree of freedom 4 . It indicates that the mean value of Solid AFO differ significantly than Articulated AFO using Flexible Ankle hinges . Further the mean value of cadence in Solid AFO whose mean value of Cadence is 91.56 which is lower than that of Articulated AFO using Flexible Ankle hinges is 104.3 (table no.1.3). It may therefore be said that Articulated AFO using Flexible Ankle hinges has found to be slightly significantly superior to Solid AFO in terms of stride length. 
Haribhau S. Dongre et.al. Comparative analysis of solid AFO vis-à-vis articulated AFO using flexible ankle hinges in children with cerebral palsy spastic diplegia age group 5-12 years in terms of gait parameters.

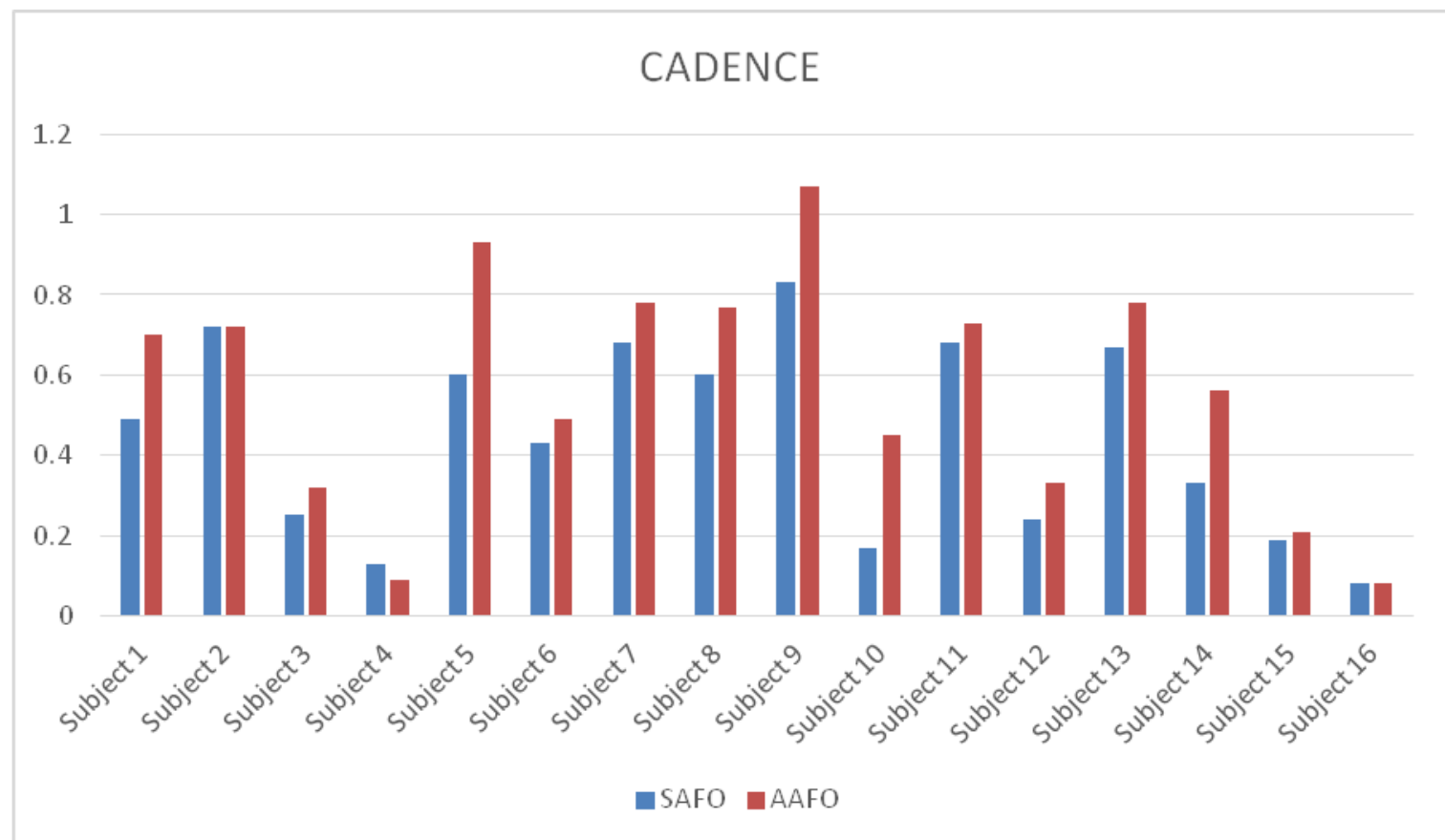

GRAPH 1.4: Cadence of Solid AFO (SAFO) and Articulated AFO using Flexible Ankle hinges (AAFO).

DEMOGRAPHICAL CHARACTERISTIC DISTRIBUTION OF SUBJECTS:

Table no.1.5 Age wise distribution of the subjects

\begin{tabular}{|l|l|}
\hline Age group (in years) & Number of Subjects \\
\hline $05-06$ & 3 \\
\hline $07-08$ & 3 \\
\hline $09-10$ & 7 \\
\hline $11-12$ & 3 \\
\hline
\end{tabular}

Agewise Distribution of Subjects

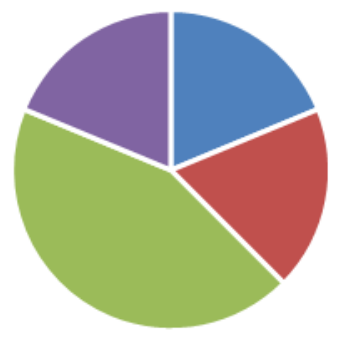

- 5-6yrs - 7-8yrs $=9-10 y r s=11-12 y r s$

Pie Chart - 1 Age wise distribution of the subjects

Table no.5 Body weight wise distribution of the subjects

\begin{tabular}{|l|l|}
\hline Body weight groups in $\mathbf{~ k g}$ & Number of Subjects \\
\hline $10-13$ & 03 \\
\hline $14-17$ & 03 \\
\hline $18-21$ & 07 \\
\hline $22-25$ & 03 \\
\hline
\end{tabular}

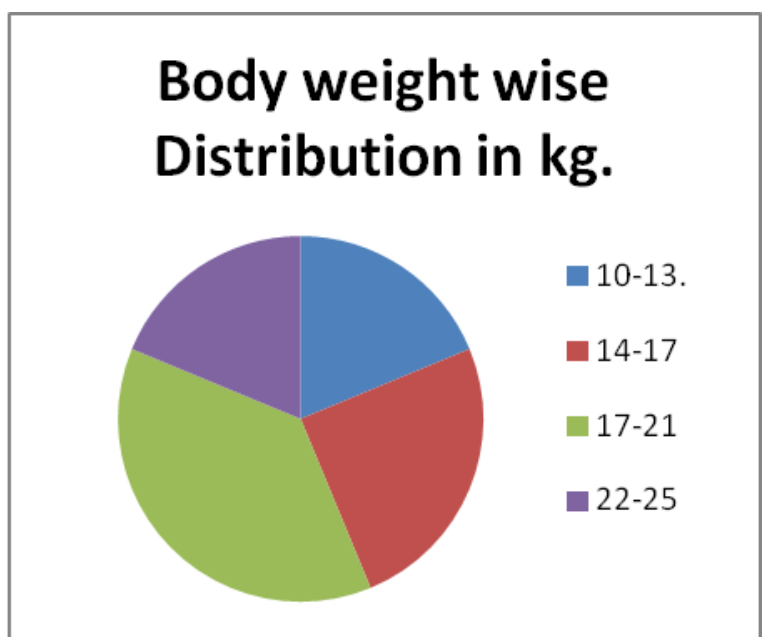

Pie Chart - 2 Body weight wise distribution of the subjects

\section{DISCUSSION}

In the study, Solid Ankle Foot Orthosis and Articulated AFO using flexible ankle hinges was used respectively in the Orthotic treatment of 16 Children with Cerebral Palsy Spastic Diplegia age group 5-12 years and comparison was made between them using Gait Parameters i.e. Step length, Stride length, Speed and Cadence.

I. Analysis of Gait Parameters (Step length, Stride length, Cadence and Speed) with both the types of Orthotic designs: 
Haribhau S. Dongre et.al. Comparative analysis of solid AFO vis-à-vis articulated AFO using flexible ankle hinges in children with cerebral palsy spastic diplegia age group 5-12 years in terms of gait parameters.

The pioneers of scientific gait analysis were Aristotle in De Motu Animalium (On the Gait of Animals) and much later in 1680, Giovanni Alfonso Borelli also called De Motu Animalium et al. It is one of the very successful methods of finding various gait parameters and also to have comparative analysis with various types of lower extremity Orthoses.

From the Table 1.1, 1.2, 1.3 and 1.4 and Graph 1.1, 1.2, 1.3 and 1.4, it is evident, that the Gait parameters i.e. Step length, Stride length, Speed and Cadence have more significant values in Articulated AFO using flexible ankle hinges than in Solid AFO. Tables shows the mean and standard deviation $( \pm S D)$ values of Step length in meter, Stride length in meter, Speed in meter per second and Cadence in steps per min for each Orthotic design. Also it is found out that as gait parameters have more significant values in Articulated AFO using flexible ankle hinges than in Solid AFO. Hence the Articulated AFO using flexible ankle hinges is more effective and suitable for Children with Cerebral Palsy Spastic Diplegia.

\section{CONCLUSION}

1. The study was performed on 16 subjects who have Cerebral Palsy Spastic Diplegia with age group 5-12 years with both Orthotic designs i.e. Articulated AFO using flexible ankle hinges and Solid AFO. It concludes that Articulated AFO using flexible ankle hinges is a better design in terms of Gait analysis as compared to Solid AFO. Also there are some more advantages such as ease and confidence while walking due to presence of Ankle movement.

2. In some patients those who are having less muscle power at Ankle joint they feel uncomfortable while using Articulated AFO with flexible ankle hinges. The reason for this may be inadequate physiotherapy exercises (as in case in Subject no.4 and Subject no.16). So due to this reason patient feel more comfortable with Solid AFO.

\section{Acknowledgement: None}

\section{Conflict of Interest: None}

\section{Source of Funding: None}

\section{Ethical Approval: Approved}

\section{REFERENCES}

1. Ries AJ, Novacheck TF, Schwartz MH. The Efficacy of Ankle-Foot Orthoses on Improving the Gait of Children With Diplegic Cerebral Palsy: A Multiple Outcome Analysis. PM R. 2015 Sep;7(9):922-929. doi: 10.1016/j.pmrj.2015.03.005. Epub 2015 Mar 11. PMID: 25771349.

2. Buckon CE, Thomas SS, JakobsonHuston S, Moor M, Sussman M, Aiona M. Comparison of three ankle-foot orthosis configurations for children with spastic diplegia. Dev Med Child Neurol. 2004 Sep;46(9):590-8. doi: 10.1017/s0012162204001008. PMID: 15344518.

3. CaliskanUckun A, Celik C, Ucan $\mathrm{H}$, OrduGokkaya NK. Comparison of effects of lower extremity orthoses on energy expenditure in patients with cerebral palsy. Dev Neurorehabil. 2014 Dec;17(6): 388-92.

4. Liu XC, Embrey D, Tassone C, Zvara K, Brandsma B, Lyon R, Goodfriend K, Tarima S, Thometz. Long-Term Effects of Orthoses Use on the Changes of Foot and Ankle Joint Motions of Children With Spastic Cerebral Palsy. J. PM R. 2018 Mar;10(3):269-275.

5. Ridgewell E, Sangeux M, Bach T, Baker R. A new method for measuring AFO deformation, tibial and footwear movement in three dimensional gait analysis. Gait Posture. 2013 Sep;38(4): 1074-6.

6. Radtka SA, Skinner SR, Johanson ME. A comparison of gait with solid and hinged ankle-foot orthoses in children with spastic diplegic cerebral palsy. Gait Posture. 2005 Apr;21(3):303-10.

7. Aboutorabi A, Arazpour M, AhmadiBani M, Saeedi H, Head JS. Efficacy of ankle foot orthoses types on walking in children 
Haribhau S. Dongre et.al. Comparative analysis of solid AFO vis-à-vis articulated AFO using flexible ankle hinges in children with cerebral palsy spastic diplegia age group 5-12 years in terms of gait parameters.

with cerebral palsy: A systematic review. Ann PhysRehabil Med. 2017 Nov;60(6): 393-402.

8. Young J, Jackson S.Improved motor function in a pre-ambulatory child with spastic bilateral cerebral palsy, using a custom rigid ankle-foot orthosis-footwear combination: A case report. Prosthet Orthot Int. 2019 Aug;43(4):453-458.

9. Kläusler M, Speth BM, Brunner R, Tirosh $\mathrm{O}$, Camathias C, RutzE. Long-term follow-up after tibialis anterior tendon shortening in combination with Achilles tendon lengthening in spastic equinus in cerebral palsy. Gait Posture. 2017 Oct;58: 457-462.

10. Degelaen M, de Borre L, Kerckhofs E, de Meirleir L, Buyl R, Cheron G, Dan B. Influence of botulinum toxin therapy on postural control and lower limb intersegmental coordination in children with spastic cerebral palsy. Toxins (Basel). 2013 Jan 11;5(1):93-105.

11. Hayek S, Hemo Y, Chamis S, Bat R, Segev E, Wientroub S, Yzhar Z. The effect of community-prescribed ankle-foot orthoses on gait parameters in children with spastic cerebral palsy. J Child Orthop. 2007 Dec;1(6):325-32.

12. Zhao X, Xiao N, Li H, Du S. Am. Day vs. day-night use of ankle-foot orthoses in young children with spastic diplegia: a randomized controlled study. J Phys Med Rehabil. 2013 Oct;92(10):905-11.

13. Hassani S, Roh J, Ferdjallah M, Reiners K, Kuo K, Smith P, Harris G. Rehabilitative orthotics evaluation in children with diplegic cerebral palsy: kinematics and kinetics. Conf Proc IEEE Eng Med Biol Soc. 2004;2004:4874-6

14. Park ES, Park CI, Chang HJ, Choi JE, Lee DS. Arch. The effect of hinged ankle-foot orthoses on sit-to-stand transfer in children with spastic cerebral palsy. Phys Med Rehabil. 2004 Dec;85(12):2053-7.

15. Carlson WE, Vaughan CL, Damiano DL, Abel MF. Am. Orthotic management of gait in spastic diplegia. J Phys Med Rehabil. 1997 May-Jun;76(3):219-25.

16. Gupta A, Srivastava A, Taly AB, Murali T. Single-stage multilevel soft-tissue surgery in the lower limbs with spastic cerebral palsy: Experience from a rehabilitation unit; Indian J Orthop. 2008 Oct;42(4):448-53.

17. Abel MF, Juhl GA, Vaughan CL, Damiano DL.; Gait assessment of fixed ankle-foot orthoses in children with spastic diplegia; Arch Phys Med Rehabil. 1998 Feb;79(2):126-33.

18. Dalvand H, Dehghan L, Feizi A, Hosseini SA, Amirsalari S; The impacts of hinged and solid ankle-foot orthoses on standing and walking in children with spastic diplegia; Iran J Child Neurol. 2013 Fall;7(4):12-9.

19. Son I, Lee D, Hong S, Lee K, Lee G; Comparison of Gait Ability of a Child with Cerebral Palsy According to the Difference of Dorsiflexion Angle of Hinged Ankle-Foot Orthosis: A Case Report; Am J Case Rep. 2019 Oct 3;20:1454-1459.

20. Jagadamma KC, Coutts FJ, Mercer TH, Herman J, Yirrel J, Forbes L, Van Der Linden ML; Effects of tuning of ankle foot orthoses-footwear combination using wedges on stance phase knee hyperextension in children with cerebral palsy - preliminary results; Disabil Rehabil Assist Technol. 2009 Nov;4(6): 406-13.

21. Buckon CE, Thomas SS, JakobsonHuston S, Moor M, Sussman M, Aiona M. Comparison of three ankle-foot orthosis configurations for children with spastic diplegia. Dev Med Child Neurol. 2004 Sep;46(9):590-8. doi: 10.1017/s0012162204001008. PMID: 15344518.

22. Kalinowski Z, Bonikowski M; Botulinum toxin $\mathrm{A}$ in the treatment of dynamic equinovarus foot in cerebral palsied children; OrtopTraumatolRehabil. 2002 Apr 30;4(2):209-17.

23. Ren K, Gong XM, Zhang R, Chen XH; Effects of virtual reality training on limb movement in children with spastic diplegia cerebral palsy; Zhongguo Dang Dai ErKeZaZhi. 2016 Oct;18(10):975979.

24. Zhang Y, Ma Y; Application of supervised machine learning algorithms in the classification of sagittal gait patterns 
Haribhau S. Dongre et.al. Comparative analysis of solid AFO vis-à-vis articulated AFO using flexible ankle hinges in children with cerebral palsy spastic diplegia age group 5-12 years in terms of gait parameters.

of cerebral palsy children with spastic diplegia; ComputBiol Med. 2019 Mar; 106:3339.

25. Westhoff B, Bittersohl D, Krauspe R; Bilateral spastic cerebral palsy with ambulatory ability (diplegia): pathophysiology, state of the art of conservative and surgical treatment and rehabilitation; Orthopade. 2014 Jul;43(7): 656-60, 662-4.

26. Rodda J, Graham HK; Classification of gait patterns in spastic hemiplegia and spastic diplegia: a basis for a management algorithm; Eur J Neurol. 2001 Nov;8 Suppl 5:98-108.
27. Aiona MD, Sussman MD; Treatment of spastic diplegia in patients with cerebral palsy: Part II; J PediatrOrthop B. 2004 May;13(3):S13-38.

How to cite this article: Dongre HS, Singh K, Bhuyar LR. Comparative analysis of solid $\mathrm{AFO}$ vis-à-vis articulated AFO using flexible ankle hinges in children with cerebral palsy spastic diplegia age group 5-12 years in terms of gait parameters. Int J Health Sci Res. 2022; 12(2): 83-90. DOI: https://doi.org/10.52403/ ijhsr.20220211 